\title{
Motif pada Seni Keramik Mambong
}

\author{
Siti Mariam Mat Noor \\ University Malaysia Kelantan
}

\begin{abstract}
Abstrak - Perbandingan antara gerabah kuno yang ada di museum Kelantan dengan gerabah kontemporer saat ini perlu dilakukan untuk membedakan atau membedakan perkembangan pola ragam hias pada produk gerabah. Sebanyak 6 pembuat keramik tradisional, 5 dosen keramik, 2 kurator museum, dan seorang direktur kerajinan diwawancarai secara tidak terstruktur. Gerabah Mambong ada 7 jenis di masa lalu, yaitu periuk, periuk tanah, periuk kukus, kendi, guri, geluk, dan wadah pengasapan. Gerabah Mambong kini hanya memiliki 5 jenis yang masih aktif diproduksi. Guri dan geluk tidak diproduksi saat ini. Gerabah lama lebih rapi dan memiliki variasi desain serta lebih tahan lama dibandingkan dengan produk baru. Gerabah lama memiliki 39 jenis motif, sedangkan gerabah baru dikurangi 27 motif yang tidak dibuat sehingga hanya tersisa 15 jenis motif. Ada juga motif yang masih dibuat sama antara gerabah lama dan gerabah baru yaitu 12 jenis motif dan hanya 3 jenis motif baru yang dibuat pada gerabah ini.
\end{abstract}

Keywords:

\section{PENDAHULUAN}

Gerabah merupakan bahan bangunan pertama yang dibuat oleh manusia yang menggabungkan empat elemen dasar yang diidentifikasi oleh orang Yunani yaitu tanah, air, api dan udara (Rice, 2005). Produk tanah liat yang telah dibentuk dan dibakar pada suhu tertentu yang biasanya pada suhu rendah. Gerabah juga merupakan bagian dari dunia keramik. Lebih tepatnya gerabah adalah keramik yang dibakar pada suhu rendah yaitu pembakaran antara $350^{\circ} \mathrm{C}$ sampai $1000^{\circ} \mathrm{C}$ (McKinnon, 1991). Tembikar tertua di Malaysia dapat ditemukan di Gua Cha pada zaman Neolitikum (Bulbeck, 2005; 2011;

2016). Gerabah telah menjadi Warisan Nasional Malaysia, terutama di enam wilayah tempat gerabah tradisional masih diproduksi; Labu Sayong dan Labu Pulau Tiga di Perak; Berenang di Pahang; Mambong di Kelantan;
Nuan dan Kudin di Sarawak; Kecor di Perlis; Kuron dan Lapohan di Sabah (Darus \& Manaf, 2005). Gerabah memiliki identitas tersendiri di setiap negara bagian di Malaysia yang mencerminkan suasana masyarakat lokalnya. Gerabah Mambong merupakan salah satu gerabah tradisional di Malaysia yang masih aktif dilakukan di Kampung Jelapang, Mambong Kuala Krai.

Dari pengamatan Siti Zainon (1986), nilai seni gerabah Mambong mengalami penurunan kualitas karena tidak dapat mempertahankan nilai bentukannya secara menurun dan keberadaannya masih belum diketahui oleh masyarakat, dibandingkan dengan labu sayong asal Perak. yang merupakan satu-satunya negara bagian atau kawasan yang masih mempertahankan nilai heritage tembikar, baik dari segi proses pembuatannya maupun desain eksteriornya. 
Penelitian ini dilakukan untuk membandingkan gerabah lama dan baru pada gerabah Mambong Kelantan. Perbandingan akan dilakukan dari segi desain, motif, dan pola ragam hias pada enam jenis gerabah tradisional Kelantan, yaitu pot tanah liat, kendi, mangkok, panci kukus, fumigator, dan pot. Gerabah dapat diartikan sebagai barang dapur yang terbuat dari tanah liat.

Menurut Ramli Bin Mat Isa yang lebih dikenal dengan sebutan 'Cikgu Ya', sejarah Gerabah Mambong berawal dari kegiatan kesenian Maimunah Binti Puteh yang terkenal dengan gelar Tok Bara telah dilanjutkan dari tahun 1868 hingga saat ini oleh mereka. Cucu mereka Tok bara adalah generasi keempat dan diwarisi oleh nenek moyangnya dalam keterampilan dasar membuat gerabah. Warga Kampung Mambong memproduksi gerabah hanya sebagai kegiatan paruh waktu untuk menambah penghasilan (Tajul Suhaizam Said, Harozila Ramli, 2011, Siti Mariam Mat Nor, 2015).

Penelitian ini mengacu pada produk yang masih diproduksi hingga saat ini yaitu tahun 2013-2015 dan dibandingkan dengan gerabah lama yaitu gerabah yang ada di Museum sesuai dengan tanggal penemuannya Penelitian ini menggunakan studi kasus dan 6 pembuat keramik tradisional, 5 dosen keramik, 2 kurator museum, dan seorang direktur kerajinan ikut serta dalam wawancara tak terstruktur.

\section{METODE}

Studi kasus dalam penelitian ini adalah studi sistematis yang mengumpulkan informasi tentang gerabah Mambong, suasana pembuatan gerabah, kejadian di balik gerabah dan pemahaman tentang sesuatu yang berfungsi atau berfungsi. Penelitian ini menggunakan pendekatan metode kualitatif yang menggabungkan beberapa langkah pengumpulan data (Bruce I. Berg, 2001).

Peneliti fokus pada individu, kelompok, seluruh masyarakat, dan teknologi data seperti sejarah kehidupan, dokumen, sejarah dan wawancara mendalam termasuk observasi partisipan (Hagan, 1993; Yin, 1994). Menurut Yin (1994) studi kasus merupakan bentuk studi yang paling tepat digunakan oleh seorang peneliti untuk memperoleh informasi yang sangat lengkap yang dikumpulkan untuk menjawab pertanyaan penelitian.

Selain itu, studi kasus juga menitikberatkan pada deskripsi yang komprehensif dan memberikan penjelasan tentang suatu peristiwa tentang tembikar Mambong secara mendalam. Penelitian ini juga mengkaji dan membandingkan fenomena produk kontemporer dalam konteks kehidupan nyata, serta batasan antara fenomena dan konteks yang tidak terlihat 
jelas. Metode pengumpulan data seperti dokumentasi, data historis, wawancara dan observasi akan menjadi fokus khusus dalam studi kasus ini (Piaw, 2006). Menurut Piaw (2006), terdapat tiga kategori studi kasus yaitu studi kasus rumit, studi kasus instrumental dan studi kasus kolektif. Peneliti menggunakan studi kasus yang rumit yang ternyata lebih tepat untuk memperdalam penelitian ini. Studi kasus adalah studi yang mengumpulkan informasi tentang kasus yang khusus, unik dan menarik

\section{HASIL DAN PEMBAHASAN}

Layu gerabah memiliki empat bentuk dasar yang dapat dikenali. Bentuk pertama adalah wadah air yang disebut kendi yang biasanya memiliki mulut lebar dan badan besar. Jenis kedua disebut periuk melayu yang bentuknya lebar dan berbingkai mulut serta bagian bawahnya membulat, biasanya dengan sisi agak miring. Keunikan gerabah khas melayu terlihat pada jenis gerabah yang ketiga. Pot tanah liat memiliki penutup dan nilai tambah karena diproduksi secara eksklusif di tembeling yaitu terenang. Ini adalah terenang dan antara cahaya oker sampai merah tua-coklat. Digunakan secara tradisional untuk membawa air, renang berbentuk di sudut dan dihiasi dengan hiasan bergerigi yang diukir di tepi bibir, di mana perubahan pada bidang terjadi secara drastis meningkat di pot dari kaki. Gerabah Indonesia seri keempat dimana-mana disebut labu botol air yang berbentuk calabash (Othman et al., 1994).

Ivor HN Evans (1922; 259-261), memberikan daftar istilah tembikar yang telah banyak digunakan di kalangan pembuat tembikar serta benda-benda yang dapat digunakan seperti pot, pot tanah, labu tanah, pot, terenang, delima, 'perbankan 'Adalah kerajinan tangan termasuk pencak (kelelawar seperti' implemnet 'dari kayu), pendedak (sebilah pisau berbentuk bambu), pengangsar (kerikil untuk memoles), pendedak (alat untuk membuat garis tegak lurus pada badan tembikar) dan bahkan pengukut ( menghilangkan tanah liat berlebih).

Gerabah Mambong Tua memiliki 7 jenis, yaitu: periuk, periuk tanah, periuk kukus, kendi, guri, geluk dan wadah pengasapan. Sedangkan gerabah baru hanya memiliki 5 jenis. Gerabah yang tidak diproduksi sekarang adalah Guri dan Geluk.3.1 Belanga (pot) 


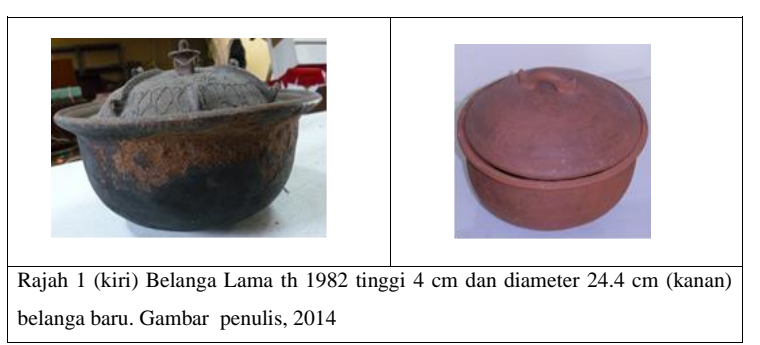

Tahun ditemukannya Geluk tua adalah tahun 1984 untuk dijadikan sebagai penyedot, penyimpan dan penampung air untuk menggantikan cangkangnya. Selain itu juga digunakan sebagai tempat penyimpanan obatobatan tradisional. Geluk memiliki bentuk bulat pada bagian tubuhnya dan memiliki mulut yang cukup lebar dari pada labu dan tidak memiliki leher maupun kepala. Warnanya hitam pada bagian tubuh produk dan memiliki motif dan corak dekoratif. Motif yang ditemukan pada lingkaran menggunakan teknik coretan. Teknik pembuatan yang digunakan adalah spiral dan pinch pinch yang seluruhnya dibuat oleh seorang pembuat tembikar. Lingkaran ini berbentuk ergonomis dan berfungsi dengan baik sebagai peralatan dapur. Bagian tubuh memiliki leher yang pendek agar lebih mudah memegang produk. Produk ini tidak memiliki penutup. Motif yang digunakan adalah kisi-kisi, rantai perak, $\mathrm{X}$, bulat dan tanduk kerbau. Ada enam tatanan pola dekoratif yang disusun secara harmonis mengelilingi produk. Menurut Ramli bin ishak, seorang pengusaha gerabah Mambong, motif ini dirancang dengan mengambil inspirasi dari lingkungan dan masyarakat di sana. Bentuk simpai memiliki daya tarik simetris di bagian mulut dan telapak kaki. Permukaan tubuh hitam hasil pembakaran jelaga dan tanah liat mempertahankan keaslian kampung Mambong. Garis motif, titik dan bentuk geometris yang menghasilkan garis-garis panjang dan susunan berpotongan juga dihasilkan berdasarkan pengamatan masyarakat melayu terhadap alam sekitar. mereka.

Menurut Ramli Bin Mat Isa, geluk semakin dilupakan dan pesanannya sudah tidak ada sejak belasan tahun lalu karena pembuat geluk sudah meninggal dunia. Generasi muda saat ini cenderung kurang memproduksinya. Dengan demikian tidak ada perbandingan antara produk geluk lama dan produk geluk baru.

Ivor. H.H. Evans (1929; 163-167) membagi pola dan desain tembikar Malaysia menjadi tiga kelas; geometri, bunga dan fauna pada rebung, siku keluang, bunga cengkeh, ampok manggis, sagi belimbing, tapak kaki sulaiman, bunga banji (swastika), daun bodi, bunga kundur, kalok paku awan, awan jawa, awan belanda, sukur bakong.

Terdapat 38 jenis Motif gerabah kuno yang dibuat dengan berbagai gaya dekoratif yang menarik dan unik. Sedangkan motif pada gerabah baru, hanya tersisa 12 jenis motif. 
Fakultas Seni Rupa dan Desain - Universitas Tarumangara

Siti Mariam Mat Noor; Halaman 32-40

Dalam Analisis Motif dan Pola Ragam hias pada gerabah Mambong, seorang pengrajin gerabah Mambong di Kampung Jelapang Halimah binti Said menyatakan bahwa pengrajin gerabah Mambong menghasilkan pola hanya sesuai dengan selera sendiri, tanpa mengetahui makna tersirat dan inspirasi dalam pembuatan motif hias dan motif hias tersebut. pola.

Terdapat 3 motif baru yang telah ditambahkan dan diaplikasikan pada gerabah Mambong Baru yaitu motif daun kecil, bunga padi dan huruf $S$, sedangkan motif yang masih dipertahankan yaitu bunga empat semburan, gunung timbul, gunung tiga dimensi, daun, siku, garis bergantian interval titik, titik, bentuk $\mathrm{V}$, interval bergantian berlapis dan rebung.Meskipun pola geometris dasar terdapat pada gerabah masih terdapat pola yang diadaptasi dari alam, seperti pecahan pola yang disebut bunga ceker ayam atau bambu. pucuk diberi nama rebung (Leng, 1994).

\begin{tabular}{|c|c|}
\hline ILUSTRASI MOTIF & KETERANGAN \\
\hline & $\begin{array}{l}\text { Bunga tanjung } \\
\text { Unsur asal- alam; tumbuhan, } \\
\text { Elemen dasar; garis berhubung, } \\
\text { Nama motif; bunga tanjung, } \\
\text { Gaya; geometrik, } \\
\text { Teknik membuat;kelar/garis/tekap. } \\
\text { Pengaruh motif : melayu }\end{array}$ \\
\hline & $\begin{array}{l}\text { Bunga lawang } \\
\text { Unsur asal- alam; tumbuhan, } \\
\text { Elemen dasar; garis berhubung, } \\
\text { Nama motif; bunga lawang, } \\
\text { Gaya; geometrik/organik } \\
\text { Teknik } \\
\text { kelar/garis/tempel/ukir. } \\
\text { Pengaruh motif : melayu } \\
\text { Bunga cengkih } \\
\text { Unsur asal-alam;tumbuhan, } \\
\text { Elemen dasar;garis berhubung, } \\
\text { Nama motif; bunga cengkih, } \\
\text { Gaya; geometrik/organik, } \\
\text { Teknik membuat;kelar/garis/tekap. } \\
\text { Pengaruh motif : melayu }\end{array}$ \\
\hline & $\begin{array}{l}\text { Bunga huruf 's' } \\
\text { Unsur asal-alam;tumbuhan, } \\
\text { Elemen dasar;garis berhubung, } \\
\text { Nama motif; 's'pilin, } \\
\text { Gaya; geometrik/organik, } \\
\text { Teknik membuat;kelar/garis/ukir. } \\
\text { Pengaruh motif : melayu }\end{array}$ \\
\hline & $\begin{array}{l}\text { Bunga kelapa } \\
\text { Unsur asal-alam;tumbuhan, } \\
\text { Elemen dasar;garis titik, } \\
\text { Nama motif; daun, } \\
\text { Gaya; geometrik/organik, } \\
\text { Teknik } \\
\text { membuat;kelar/garis/tempel/ukir. } \\
\text { Pengaruh motif : melayu }\end{array}$ \\
\hline & $\begin{array}{l}\text { Bunga rebung } \\
\text { Unsur asal-alam;tumbuhan, } \\
\text { Elemen dasar;garis berhubung, } \\
\text { Nama motif; pucuk rebung, } \\
\text { Gaya; geometrik/organik, } \\
\text { Teknik membuat;kelar/tekap/warna. } \\
\text { Pengaruh motif : melayu }\end{array}$ \\
\hline
\end{tabular}




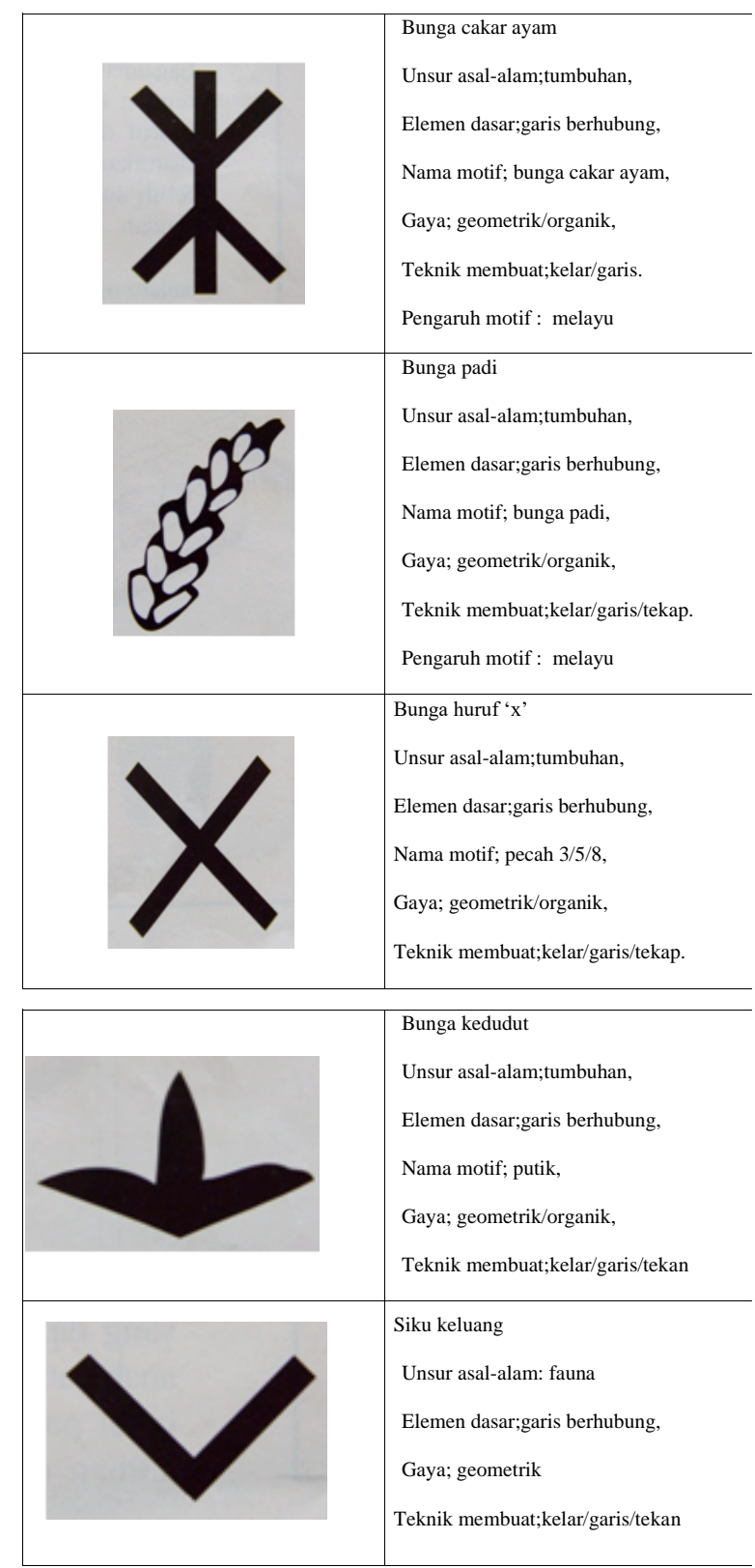

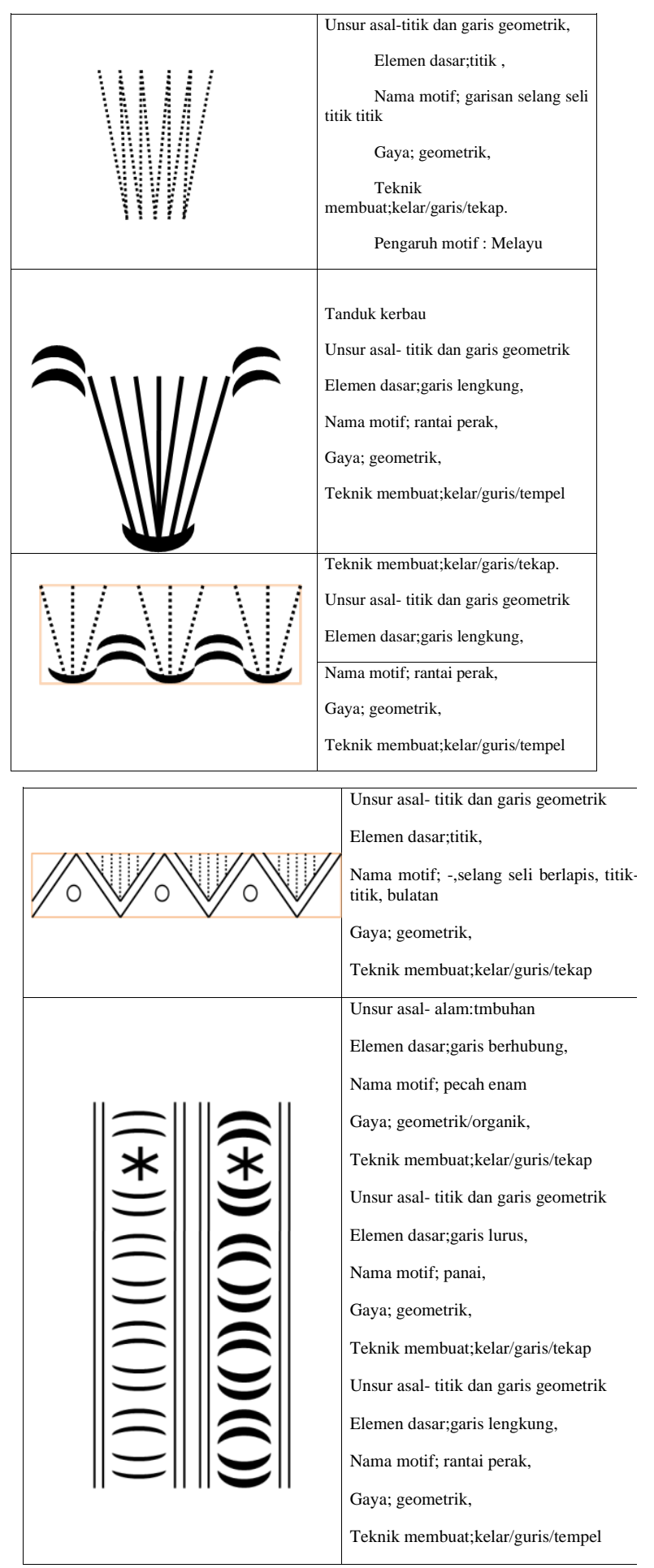

\section{KESIMPULAN}

Dari hasil studi kasus menunjukkan perbandingan gerabah lama dan baru serta gerabah terbukti yang memiliki nilai seni. Desain dan motif dekoratif terbaik ada pada gerabah tua. Ini mencerminkan hasil karya 
yang halus dan penuh dengan makna tersirat. Desain gerabah lama unik dan bodinya lebih kuat dari yang baru. Dari pengamatan, hasil akhir produk gerabah lama lebih baik dari gerabah baru. Ada beberapa produk gerabah baru seperti wadah fumigasi dan panci kukus yang menggunakan cetakan yang menunjukkan produk akhir yang berantakan. Penggunaan motif ini diambil dari lingkungan (Leng, 1994) kecualimotif spiral Cina.Dekorasi pada gerabah terungkap motif dan corak yang bergaya seperti bunga cengkeh, bunga padi, bunga tanjung, adas bintang dan sejenisnya yang umum pada gerabah. Bunga layu (Leng, 1994) Penelitian ini juga menunjukkan motif bunga yang sama seperti bunga tanjung, bunga adas bintang, bunga cengkeh, bunga sembur empat, bunga sembur enam, bunga sembur delapan, bunga kelapa, bunga rebung, bunga ceker ayam, bunga padi, bunga kedudut. Secara umum motif di Mambong memiliki dominasi bunga dan geometri, namun lebih sedikit pada fauna.

Dari segi kegunaan dan fungsi gerabah, studi kasus menunjukkan bahwa gerabah mambong tidak lagi digunakan sebagai peralatan dapur dan hanya digunakan sebagai perhiasan saja. Masyarakat kampung jelapang, mambong sendiri menggunakan produk plastik dan tembaga.penggunaan gerabah semakin menurun karena telah diambil alih oleh bahan baru yang lebih awet, mudah dibuat, cepat didapat dan dapat dengan harga yang terjangkau tersebut. Seperti aluminium, kaca, dll. Sikap pengusaha yang tidak berani mencoba sesuatu yang baru membuat gerabah mambong sulit diberikan peningkatan dan nilai yang pantas. Minimnya penggunaan motif dan corak ragam hias seiring dengan menurunnya pesanan menunjukkan bahwa tingkat respon terhadap seni kerajinan gerabah tradisional sangat rendah. Hal ini menunjukkan tandatanda awal kesenian gerabah tradisi melayu kelantan semakin menurun dan cenderung menghilang seiring berjalannya waktu.

Ornamen memiliki arti yang sama dengan 'ornamen' dalam bahasa yunani. 'Ornament' atau 'ornare' berarti menghiasi atau menghiasi sebuah karya seni. Dalam produksi suatu karya seni dekorasi merupakan suatu keharusan untuk mengisi kekosongan pada permukaan produk agar indah. Pola dekoratif juga memiliki makna simbolik literal dan implisit. Alam digunakan sebagai sumber inspirasi dalam pembuatan gerabah sedangkan budaya melayu yang sarat tradisi, kepercayaan dan islam menjadi rujukannya. Penciptaan representasi simbolik dalam seni gerabah melayu lahir dari inspirasi dan inspirasi 'rice spirit'. (salwa pert, 2010). Penciptaan dan penggunaan simbol adalah sesuatu yang unik 
dalam perilaku dan pemikiran manusia (cassirer, 1944)

\section{DAFTAR PUSTAKA}

Bruce L. Berg. (2001). Qualitative Research Method FOr The Social Sciences. (Sarah L. Kelbaugh, Ed.) (Fourth). California State Univesity, Long Beach.

Cassirer, E. (1944). An Essay on Man, New Haven: Yale University Press.

Kee M. Y. (2004). Straits Chinese Porcelain: A Celebration of a Unique Malaysian Heritage Showcasing the Datin Seri Kee Ming-Yuet Collection. Kee Ming-Yuet Sdn. Bhd.[and] Cross Time Matrix Sdn. Bhd..

Evans, I. H.N. (1922). The Potting Industry at Kuala Tembeling. Journal of the Federated Malay States Museum, 9, 259261.

Evans, I. H.N. (1929). Some Malay Pattern and Design. Journal of the Federated Malay States Museum, 15, 163-167.

Leng, Y. J. (1994). The Crafts of Malaysia. (S. Bhanu, Ed.) Singapore: Tien Wah Press.

Nor Azlin Hamidon. (2002). Seni Rupa Melayu. In Prof Madya Dr. Ton Ibrahim (Ed.), Kesenian Melayu (pertama, p. 84). Akademik Pengajian Melayu, Universiti Malaya.

Piaw, C. Y. (2006). Kaedah Penyelidikan. In Kaedah dan Statistik Penyelidikan Buku 1. Mc. Graw-Hill Book (Malaysia).

Salwa Ayob. (2010). Tembikar Tradisi Melayu
Perak. "Warisan Budaya Negeri

Perak,"Simposium .

Siti Maryam Ali Yasin. (2011). Falsafah Dan Prinsip Senireka Di Dalam Seni Tradisi Tembikar Melayu. Prosiding Seminar Antarabangsa Warisan Dan Nusantara.

Siti Zainon, I. (1986). Reka Bentuk Kraftangan

Melayu Tradisi. Universiti Kebangsaan

Malaysia.\{Bibliography\}

Syed Ahmad Jamal. (1992). Rupa dan Jiwa.

(Dewan Bahasa dan Pustaka, Ed.). Kuala Lumpur.

Tajul Suhaizam Said, Harozila Ramli, M. F. S. (2011). Local Genius of Mambong Pottery in Kelantan, Malaysia, 1(21), 147-155.

Yin, R. (1994). Case study research: Design and methods (2nd ed.). Beverly Hills, CA: Sage Publishing.

Evans, I. H.N. (1922). The Potting Industry at Kuala Tembeling. Journal of the Federated Malay States Museum, 9, 259-261.

Evans, I. H.N. (1929). Some Malay Pattern and Design. Journal of the Federated Malay States Museum, 15, 163-167.

Leng, Y. J. (1994). The Crafts of Malaysia. (S. Bhanu, Ed.) Singapore: Tien Wah Press. 
May, G. C. (2008). Tembikar Baba dan Nyonya:

Corak dan Motif Porselin Famille Rose

(Baba and Nyonya Ceramics:Designs

and Motifs of the Famille Rose

Porcelain. Wacana Seni Journal of Arts

Discourse, 7, 47-90.

Nor, S. M. (2015). Reka Bentuk dan Ragam Hias

Tembikar Mambong: Satu

Perbandingan Lama dan Baharu. Kota

Bharu: Universiti Malaysia Kelantan. 